\title{
Perceived Susceptibility to Mental Disorders among Marijuana Smokers Attending a Tertiary Institution
}

\author{
N Albarus, P Whitehorne-Smith, WD Abel
}

\begin{abstract}
Objective: This exploratory qualitative study sought to investigate the question of 'how do marijuana smokers at a tertiary institution perceive their susceptibility to mental illness?'.

Methods: The study utilized an instrumental case study design. Convenience and snowball sampling techniques were employed to garner participants. Inclusion criteria were that the participants had to be enrolled at a tertiary institution and had smoked at least an average of one spliff of marijuana per week for at least one year. Data collection comprised 12 in-depth interviews with the participants (six male and six female), direct observation, and content analysis of Jamaica's amended Dangerous Drugs Act of 2015.

Results: Emergent were themes of personal experience, social environment and low-risk perception for mental illness.

Conclusion: Risk perception for mental illness was low. Participants perceived marijuana use as a viable coping strategy and demonstrated limited understanding of the negative effects of smoking marijuana.
\end{abstract}

Keywords: Marijuana smokers, mental disorders, perceived susceptibility

\section{Susceptibilidad a los Trastornos Mentales Percibida entre los Fumadores de Marihuana que Asisten a una Institución Terciaria}

\author{
N Albarus, P Whitehorne-Smith, WD Abel
}

\begin{abstract}
RESUMEN
Objetivo: Este estudio cualitativo exploratorio buscó investigar la repuesta a cómo los fumadores de marihuana en una institución terciaria perciben su susceptibilidad a la enfermedad mental.

Métodos: El estudio utilizó un diseño de estudio de caso instrumental. Técnicas de muestreo por conveniencias y muestreo de bola de nieve fueron empleadas para reunir a los participantes. Los criterios de inclusión eran que los participantes tenían que estar matriculados en una institución terciaria y haber fumado por lo menos un promedio de un porro de marihuana por semana durante al menos un año. La recopilación de datos abarcó 12 entrevistas en profundidad con los participantes (seis hombre y seis mujeres), observación directa y análisis de contenido de la Enmienda a la Ley de Drogas Peligrosas de Jamaica de 2015.

Resultados: Los temas que surgieron fueron asuntos de experiencia personal, ambiente social y percepción de bajo riesgo de enfermedad mental.
\end{abstract}

From: Department of Community Health and Psychiatry, The University of the West Indies, Mona, Jamaica, West Indies.
Correspondence: Miss N Albarus, Department of Community Health and Psychiatry, The University of the West Indies, Mona, Kingston 7, Jamaica, West Indies. Email: albarus.n@gmail.com 
Conclusión: La percepción del riesgo de enfermedad mental fue baja. Los participantes percibieron el uso de marihuana como una estrategia viable de ayuda, y mostraron una comprensión limitada de los efectos negativos de fumar marihuana.

Palabras clave: Fumadores de marihuana, trastornos mentales, susceptibilidad percibida

West Indian Med J 2017; 66 (5): 563

\section{INTRODUCTION}

Marijuana use is prevalent in Caribbean culture, especially among youth, who corroborate increased ease of access and decreased discernment of risk (1). The regular use of marijuana in adolescence is of particular concern, as it is associated with an increased likelihood of damaging consequences and an increased risk of mental health problems (2). This situation is further coloured by the fact that marijuana use has been decriminalized in Jamaica, under the stipulations that mainstream cultivation, possession of more than two ounces and marijuana trading will remain illegal (3).

Frequent marijuana use is associated with anxiety, depression, schizophrenia and psychosis (4). Nevertheless, causality has not been established, and association with genetic predisposition has not been confirmed. With $21.5 \%$ of Jamaican youth using marijuana (5), it is valuable to note the intentions of these adolescents within the legal framework. Although this issue has been explored in the Caribbean with adolescent students, the studies primarily focussed on teenagers within high school populations. While students at this level are indeed crucial to be examined, university students also merit concern.

Substance abuse is thought to peak between the ages of 18 and 25 years (6), a common age range for young university students. This is particularly evident within the Latin-American population (7). These students are in a new and potentially stressful environment and have amplified access to drugs, ergo they are vulnerable. Dhanookdhary et al reported $13 \%$ of Trinidadian undergraduate students having used marijuana within a six-month period. Of the aforementioned cohort, $43 \%$ reported chronic use (past-month prevalence). The year 2012 saw an increase in past-month prevalence from 2009, within Latin America. In Bolivia, it increased from $0.76 \%$ to $1.45 \%$; in Colombia, from $5.27 \%$ to $7.14 \%$; in Ecuador, from $1.68 \%$ to $3.67 \%$; and in Peru, from $1.00 \%$ to $1.62 \%(7)$.

It is irrefutable that drug use at a young age puts one at greater health risks. However, other biological and environmental stimuli may exist, and marijuana's role in the interplay is uncertain. It is worthwhile to probe if these youths believe they are at the risk of mental illness and whether this perception influences use. The public remains uninformed about the definite implications of smoking marijuana, thus an 'ignorance is bliss' attitude prevails. The popular notion seems to be that marijuana is a harmless pleasure, and access to it should not be regulated at all. Nonchalance remains saturated, and smokers are increasingly vulnerable. Research suggests that about 1 in 11 users becomes addicted to marijuana $(8,9)$. Furthermore, other variables must be explored, particularly the drug's interactions and role in the development of mental illness. A correlation between the development of mental illness and marijuana use has been posited by research. An increased frequency of use is linked to an amplified risk of psychosis, as well as perceived effects of depression, paranoia and loss of control $(4,10,11)$.

Within the Jamaican context, clinical evidence does not prove causality; thus, more rigorous study is required $(12,13)$. In light of Jamaica's developing legal landscape surrounding marijuana use and conversation about its probable medicinal value on a global scale, marijuana has become appealing beyond its ordinary recreational use and psychoactive effects. This research sought to explore the question of 'how do marijuana smokers at a tertiary institution perceive their susceptibility to mental illness?'.

\section{SUBJECTS AND METHODS}

This was an exploratory study utilizing an instrumental case study approach. It focussed on the participants' subjective experiences and interpretations, in relation to the overarching phenomenon of marijuana smoking.

The inclusion criteria were that participants were enrolled at a tertiary institution and had been smoking at least an average of one spliff of marijuana per week for at least one year. Six males and six females were interviewed to ensure a gender balance. Non-probability sampling, specifically convenience sampling and 
snowball sampling, was employed. Convenience sampling was utilized to access participants in 'hotspots' on campus, where smoking was rampant. Subsequently, a 'gatekeeper' was identified. This person had access and fidelity among marijuana smokers and proved useful in identifying participants for the study quickly (snowballing).

The interview comprised predetermined questions and topics asked in a systematic and consistent order. With the freedom to digress, the interviewer was able to probe beyond the answers to the prepared and standardized questions. Secondly, direct observation was employed. This entailed detailed field notes of behaviours, events and annotations collected in an unobtrusive manner from two of the campus 'hotspots'. Finally, a content analysis of Jamaica's amended Dangerous Drugs Act of 2015 was conducted.

\section{Data analysis}

Following transcription of the interviews, the data were analysed. Similar and unique instances from the data were amassed, while emergent issue-relevant meanings were noted. Patterns among categories were noted through bracketing and coding. The researcher identified all preconceived ideas about the phenomenon of marijuana smoking, then mentally discarded them in an effort to approach the data in a pure and unbiased form.

Coding was done at the open, axial and selective levels. This involved deriving categories from codes, and themes from categories. In vivo coding was also used, as there were no pre-existing themes. A total of 101 codes were collapsed into 16 categories and, finally, three themes. The findings were then reported in a descriptive way.

\section{RESULTS}

The question under scrutiny was 'how do marijuana smokers at a tertiary institution perceive their susceptibility to mental illness?'. The methods used to offer insight into the phenomenon under study were field notes based on observation, in-depth interviews and content analysis of Jamaica's amended Dangerous Drugs Act of 2015. The information is presented in aggregate below using diagrams, direct quotes from respondents, observations from the field and excerpts from the Dangerous Drugs Act of 2015 analysed.

Regarding the age distribution of the participants, the youngest and oldest participants were 21 and 25 years old, respectively, with a mean age of 23.33 years. Three core themes emerged in response to the central research questions, namely, personal experience, social environment and perception of harm.

\section{Personal experience}

Personal experience with marijuana was the primary theme emerging from the study and, evidently, the rationale for the continued practice of smoking. It encompassed an analysis of perceived benefits, drawbacks and ways of coping. One participant described the experience:

I found most of my reflective moments tend to happen when I smoke...Awful things going wrong it a mad me and I just go burn a spliff and it calms me down. Then I see I am my biggest critic because when I think reflective, I try to sympathize with myself. I am still going to have to deal with it and to get through it and to try to develop a plan to move forward. Sometimes I don't always stick to the plan because things happen and the vibes change after a while.

Numerous benefits were identified by the participants, leading the researcher to garner that the use of marijuana assisted in quelling thoughts and afforded them clarity. Other identified benefits include, among others, the affordability of sustaining the habit of smoking marijuana, the assistance it gave in quitting alcohol, the assistance it gave in maintaining a healthy diet, the calming effect it had, how it kept persons occupied and out of harm's way, unlocked creativity and talents, better sleep, preserving body heat in the cold, and enhanced sexual experiences. Some participants reported as follows:

"Um, I don't know how allyuh say it but if something going on normally I would get real root up and thing about it nah. I more see what's going on. I see a situation happening, sit back and analyse the situation and decide a course of action, rather than immediately jumping to an action. It [weed] make you think a lot more before you act."

"People have to understand smoking marijuana is not just for recreational purposes it's also for a meditative purpose. Some of the times if you listen to the real elders them talk about it. You have to just meditate and have a conscious mind because one thing I think probably maybe is a myth or there may not be any grounds for it but it's something I came to realize and even through reasoning with friends, marijuana does not necessarily change you but it makes what was under the surface come forward."

“...if me happy and me smoke weed, me happier!...If me sad, it can help me take me mind offa weh me sad bout, as well as it can focus me mind pon weh me sad bout. But me 
control it so if me want it fi take me mind offa it, it will take me mind offa it."

“...me a go a me bed like sinting to 3 am and me a say to myself seh bwoy me affi go wake up back 6 o'clock tomorrow. Me naaw go have no use to myself. So me get the weed, take me draw, feel nice... Laugh, have fun, bond, hug up and whatever and wake up back $6 o^{\prime}$ 'clock it comin like a eight and ten hour me sleep."

Secondly, some side-effects of smoking marijuana were highlighted. Notably, these drawbacks did not outweigh the perceived benefits of smoking. These sideeffects were reported in two major forms: (a) physical, namely, poor short-term memory, chest tightness, shortness of breath, thirst; and (b) behavioural, namely, social withdrawal, feelings of lousiness, impaired view of reality and bizarre behaviour. Two participants shared the following:

"It slows me out, like what's the word I'm looking for? It dulls me mentally. I'm not as sharp as I was when I was sober. So it slows my thinking process."

"It [smoking] depends on what I have to do for the day or the week or the month. Smoking makes me very unproductive so me kinda see it as a reward then."

Finally, smoking marijuana as a coping mechanism was apparent in the study. It was the preferred 'guilty pleasure' for hassles associated with school, pain relief, regulating emotions and dealing with unwelcome emotions. One participant described it this way:

Probably you get some bad news or you just angry or any kind of thing weh just heightens my emotions, I want spliff. So even if me a celebrate, me want a spliff. If me sad, I want a spliff. Any kind of emotions outside of the indifferent, I want a spliff so but it has to be a burst of emotion...

\section{Social environment}

The secondary theme emerging from the study encapsulated family initiation, peer influence and community sanction, and can be viewed as the external impetus to one's personal experience. Firstly, all participants noted that they were introduced to marijuana smoking by a member of their household: grandmothers, fathers, uncles, cousins and, most prevalently, older brothers. They noted that their family members indulged it as a means of recreation, stress relief, celebration or reward for good behaviour. Interestingly, only parents disapproved of their children smoking. It was also sanctioned as a religious practice by the Dangerous Drugs (Amendment) Act 2015 which states that 'adherents of the Rastafarian faith will also be permitted to smoke ganja for sacramental purposes in locations registered as places of Rastafarian worship'. Two participants shared:

"When I finish Grade Six Achievement Test, my brother gave me a present and that present was a spliff. I was maybe about [pause] 10 or 11 years old."

"I think I do have a predisposition, not for mental disorders but for smoking because both my grandparents did it so much quite openly. My grandmom buy it, she a Christian and she sell it. Mama. All my uncles do it and it was just something for me and my family. We have a strong influence of Rastafarianism so that's a part of it and it's in my community as well. It's not something that people look down on. Everybody smoke. Every little young boy smoke and it's not something and then is a lot of women smoke too..."

Secondly, peer influence was noted as a supplementary factor to the continued use of marijuana. Although all participants declared that they were not being pressured, they credited smoking as a bonding activity among peer groups, and noted that failure to participate meant exclusion. Reportedly, the outcomes of smoking marijuana with friends were deep social exchanges, higher reasoning, camaraderie, information sharing and exposure to different types and methods of smoking. As a result, other friends were initiated into the practice to deepen the bond. For example, one participant shared:

My closest friends is because of smoking. It's what brought us together. From the day we share the same spliff, it bring people together - unite people. The blackest and whitest men smoking together. And if you there with someone and you smoking you will more open up than if you smoking by yourself and someone there.

Finally, family initiation and peer influence were compounded by incessant community sanction. In childhood, participants' geo-social boundaries endorsed the habit of smoking marijuana; in college years, it was made readily accessible and cheap, thus normalizing the practice. One participant shared:

But like people round me smoke. People inna me community smoke. The high school weh me go no smoking never di deh or nutn but it did always deh roun so loke me know seh is like a shadow. So like me know seh smoking exist and me know seh as me grow old and grow more openminded me woulda want fi try it. It's like drinking. You know, u drink? It's accessible. So like you buy it anywhere. Worse now me deh pon the campus, can buy it anywhere. And weh me a find out, everybody smoke weed. Both student and people weh a no student. So if you no know weh $f i$ get it just ask smaddy fi gi u some or ask smaddy weh $u$ can get it and dem will tell you. 


\section{Risk perception for mental illness}

The final theme emanating from the study was risk perception. This theme was the direct amalgamation of the social environment and personal experiences (Figure).

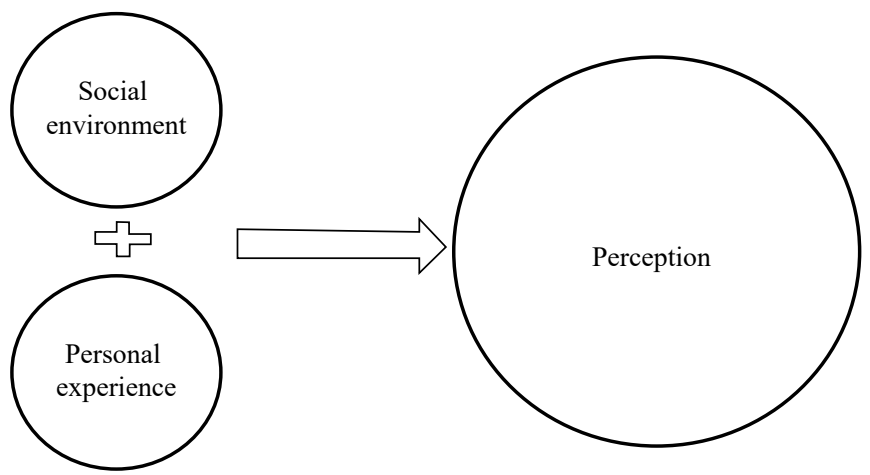

Figure: Risk perception model of perceived susceptibility to mental illness.

No participant deemed themselves to be at any kind of risk of developing a mental disorder in the short or long term. Interestingly, they all noted the possibility that a mental disorder could develop, accelerate or be exacerbated; however, they all believed that their exercise in due diligence had provided a safeguard for them. Participants noted that predisposition to a mental disorder made one vulnerable; thus, they alleged that such persons should avoid marijuana use at all costs. They also highlighted the importance of noting one's reactions to weed and those who 'cannot manage' it should refrain from its use. One participant shared:

"I can't exactly pinpoint the data just yet but I know it is said that if you have a predisposition to stuff like schizophrenia or different disorders like that, it can trigger that off so even if you were living normally then and you start smoking heavily, it can be a trigger. But I don't know what the data is like as it relates to people who don't have the predisposition and the marijuana actually creating the mental disorder."

"Like when you smoke it make you constantly think of one problem. Yea so if you no strong within yourself, you see me, you naaaw go can manage. Me no recommend it to people weh too emotional."

Furthermore, they each posed evidence of vigilance in their marijuana use, which they all expected would act as a buffer against the threat of mental illness. This included playing games while 'high' to keep their minds sharp, testing their initial reactions to marijuana after taking breaks, experimenting with different dosages, purchasing marijuana from reliable sources and rolling it themselves. Notably, men were far more vigilant in this respect than women, who admitted to relying on others to purchase and roll their weed. One participant shared:
I have to get assurance from someone. I won't just buy weed because they sell weed here. I have to be careful and double-check. Have to be smart. That's it. [Pause.] Build your own spliff and roll your weed as much as possible but they can put it in your food or in your drink so you have to be smart.

They also identified alternative methods of marijuana use, as smoking was repeatedly identified as a harmful habit. This included plans to shift gradually to using teas and brownies and steaming to attain the 'high' without the harmful ramifications of smoking.

\section{DISCUSSION}

The aggregated findings of the present study illustrated that personal experience with marijuana and participants' social environment strongly influenced their perception of susceptibility to mental illness. The main findings of the study indicated that the perceived susceptibility to mental illness was very low among marijuana smokers at a tertiary institution.

\section{Personal experience}

Participants highlighted numerous benefits and negative side-effects of smoking marijuana. Examples of the former include its affordability, accessibility and effect as a sleeping aid; as such, it serves as a coping mechanism for many of its users. This is supported by Copeland et al who noted that smoking was valuable for stress relief, achieving relaxation, eliminating negative emotions or for fun at social events (14).

In contrast, the findings in this study also supported reports in the literature related to the negative side-effects of smoking marijuana, such as poor shortterm memory, chest tightness, shortness of breath, social withdrawal, feelings of lousiness, impaired view of reality and strange behaviour $(10,11)$. Nonetheless, marijuana smokers have seemingly done a cost-benefit analysis and deduced that the negative effects are worth the advantages. Mainly, the affordability of sustaining the habit of smoking marijuana, the assistance it offers in quitting alcohol and maintaining a healthy diet, its calming effect, keeping persons occupied and out of harm's way, unlocked creativity and talents, better sleep, preserving body heat in the cold, and enhanced sexual experiences, among others, made it worth the costs (14).

\section{Social environment}

Social exchanges are seen as motivation to smoke for the purposes of fun, relaxation and connection or reasoning on a deeper level $(10,15,16)$, a point which was 
evident in the findings. Normalization occurs within social groups; in particular, family and close friends were noted to introduce and perpetuate marijuana use, respectively. It was highlighted that there was no blatant pressure from social groups, but more of an expectation. This demonstrated how the direct and indirect burden of peer expectation could lead to a sense of resignation. The social gatherings described perpetuated marijuana smoking, thereby making it harder to resist. Interestingly, the illegality of the drug did not serve as a deterrent. Thus, with the family as the initiator, the peers as influences and the community as a major endorser, prompts to smoke marijuana would be inherent in the construction of knowledge as a child, since social interaction and culture guide cognitive development.

\section{Perception of susceptibility to mental illness}

Notably, participants articulated the physical and mental harm of smoking marijuana. This is noteworthy because the harm was not perceived to be critical enough to motivate them to stop. Despite all the side-effects articulated by the participants themselves, generally, marijuana was not seen as a high-risk drug. In fact, perceptions ranged from apathy about the effects to reverence for the drug. In accordance with a study by Aryal et al, an optimism bias was prevalent in the findings (17). This bias protected them from even considering that their risk of developing a mental disorder would increase with the use of the drug, thus they had no apparent reason to change their behaviour. Therefore, risk perception was low, resulting in a lack of motivation to change behaviour.

\section{Limitations}

The case study design could only suggest what would be found in other organizations. A phenomenological study would be more expansive by allowing for more participants and a longer time period of study. Secondly, prior knowledge of mental disorders was assumed by the researcher. However, upon entering the field, the researcher realized this was not the case. Therefore, participants were unable to give informed responses when asked how mental illness was affected by marijuana smoking.

\section{CONCLUSION}

Arising from the literature and the field is the role of the family, friends and community in introducing a person to marijuana prior to the teenage years. In addition, the habit is developed and sustained in university. Personal experience with smoking marijuana as a coping mechanism and a beneficial practice outweighed the drawbacks outlined and also influenced the choices made about frequency of use, sourcing marijuana and being vigilant while 'high'. Definitive knowledge of the effects of smoking marijuana on mental health was lacking; however, there was suspicion of its relationship with schizophrenia and psychosis.

This research highlighted the paucity of literature on the influences of the family and friends in marijuana smoking. It spoke to the need for school- and community-based prevention efforts to focus on families as well as peers.

\section{REFERENCES}

1. Douglas K. Drug use behaviours among students in the Caribbean (PowerPoint slides). 2014. Available from: http://www.cicad.oas.org/ apps/Document.aspx?Id=3070.

2. World Health Organization. Mental health action plan 2013-2020. Available from: http://apps.who.int/iris/handle/10665/89966.

3. Ministry of Justice, Jamaica. Fact sheet on the Dangerous Drugs (Amendment) Act 2015. Available from: http://moj.gov.jm/sites/default/ files/Dangerous\%20Drugs\%20Amendment \%20Act \%202015\%20 Fact\%20Sheet_0.pdf.

4. Moore T, Zammit S, Lingford-Hughes A, Barnes T, Jones P, Burke M et al. Cannabis use and risk of psychotic or affective mental health outcomes: a systematic review (abstract). The Lancet 2007; 370: 319-28.

5. Atkinson U. Substance use among youth in Jamaica. A review of research conducted by National Council on Drug Abuse (PowerPoint slides). Kingston: National Council on Drug Abuse; 2012.

6. Dhanookdhary AM, Gomez AM, Khan R, Lall A, Murray D, Prabhu $\mathrm{D}$ et al. Substance use among university students at the St Augustine Campus of The University of the West Indies. West Indian Med J 2010; 59: 641-9.

7. Hynes M, Demarco M, Araneda JC, Cumsille F. Prevalence of marijuana use among university students in Bolivia, Colombia, Ecuador, and Peru. Int J Environ Res Public Health 2015; 12: 5233-40.

8. Anthony J, Warner L, Kessler R. Comparative epidemiology of dependence on tobacco, alcohol, controlled substances, and inhalants: basic findings from the National Comorbidity Survey. Exp Clin Psychopharmacol 1994; 2: 244-68.

9. Lopez-Quintero C, Pérez de los Cobos J, Hasin DS, Okuda M, Wang S, Grant BF et al. Probability and predictors of transition from first use to dependence on nicotine, alcohol, cannabis, and cocaine: results of the National Epidemiologic Survey on Alcohol and Related Conditions (NESARC). Drug Alcohol Depend 2011; 115: 120-30.

10. Ministry of Health, Manatu Hauora, New Zealand. Research into knowledge and attitudes to illegal drugs - a study among the general public and people with experience of illegal drug use. Available from: https:// www.health.govt.nz/system/files/documents/publications/research-intoknowledge-attitudes-illegal-drugs-jul09.pdf.

11. Diplock J, Cohen I, Plecas D. A review of the research on the risks and harms associated to the use of marijuana. J of Global Drug Policy and Practice 2009; 3. Available from: http://www.globaldrugpolicy.org/ Issues/Vol\%203\%20Issue\%202/Review\%20of\%20the\%20Research. pdf.

12. Abel WD, Sewell C, Eldemire-Shearer D. Decriminalization of marijuana: is this a realistic public mental health policy for Jamaica? West Indian Med J 2011; 60: 367-70.

13. Hickling F. The mental health perspective of cannabis use in Jamaica. In: Lowe H, Morrison E. Ganja: the Jamaican connection. Kingston: Pelican Publishers Limited; 2001: 129-38.

14. Copeland J, Swift W, Clement N, Reid A. Young cannabis users' attitudes and beliefs about cannabis and school drug education. New 
South Wales, Australia: New South Wales Department of Education and Training; 2001. Available from: https://www.researchgate.net/ profile/Wendy_Swift/publication/237665297_C_Young_cannabis_ users\%27_attitudes_and_beliefs_about_and_school_drug_education/ links/00b7 d52840a 738 b 1a9000000/C-Young-cannabis-users-attitudes-and-beliefs-about-and-school-drug-education.pdf.
15. Highet G. Cannabis and smoking research: interviewing young people in self-selected friendship pairs. Health Educ Res 2003; 18: 108-18.

16. Bahr SJ, Hoffmann JP, Yang X. Parental and peer influences on the risk of adolescent drug use. J Prim Prev 2005; 26: 529-51.

17. Aryal UR, Petzold M, Krettek A. Perceived risks and benefits of cigarette smoking among Nepalese adolescents: a population-based cross-sectional study. BMC Public Health 2013, 13: 187. 